\title{
Meningkatkan Nilai-Nilai Moral Anak melalui Metode Cerita Di Kelompok Bermain Amanah Tlogowungu Pati
}

\section{Dwi Sulistyaningrum}

Institut Pesantren Mathali'ul Falah

Email: dwisulistyaningrum875@gmail.com

\begin{abstract}
This study aims (1) To know the moral values of children aged 3-4 years in KB Amanah Guwo Tlogowungu Pati Lesson Year 2016/2017. (2) To know the improvement of moral values of children through the method of ceritadi KB Amanah Guwo Tlogowungu Pati Lesson Year 2016 / 2017. Metode this research using classroom action research. This research is conducted in two stages, that are cycle I and cycle II. The subjects of this study are students of Amanah Playgroup Group age 3-4 Guwo Tlogowungu Pati as many as 20 students. The results of this study indicate that storytelling can improve the moral values of children carried out with two cycles, the first cycle is done by telling stories directly, sikus II is done with the book cerita. From data analysis and observation through storytelling showed an increase from pre cycle $35 \%$ children which is complete in moral values, rises in the first cycle to $60 \%$. It means an increase of $25 \%$. And in the second cycle increased to $85 \%$ and an increase until $60 \%$. The results achieved in cycle II already meet the determined completion target, which is $80 \%$ of the total children, they get the value with the category of the total value of 85 . The increase of this average value proves that storytelling can improve the moral values of children.
\end{abstract}

Keywords: early childhood, moral values, storytelling activities. 


\section{PENDAHULUAN}

Masa usia 0-6 tahun merupakan masa dimana anak menjalani tumbuh dan kembang secara pesat. Baik secara fisik maupun psikologis. Pada masa ini kepekaan atau sensitivitas anak tinggi dalam merespon lingkungannya termasuk dalam merespon nilai-nilai moral dan agama. Menurut Kohlberg perkembangan moral anak usia prasekolah (PAUD) berada pada tingkatan yang paling dasar yang dinamakan dengan penalaran moral prakonvensional. Pada tingkatan ini anak belum menunjukkan internalisasi nilai-nilai moral (secara kokoh). Namun sudah mulai menyerap dan menyimpan dalam memori otaknya tentang moral dan agama yang patut dan tidak melalui hukuman dan kepatuhan (punishment dan obedience orientation) serta individualisme dan orientasi tujuan instrumental (individualism and instrumental purpose) (Siti Aisyah, 2008: 7.3).

Hal tersebut juga sama seperti yang diungkapkan oleh Montessory bahwa masa kanak-kanak merupakan masa menyerap semua hal-hal yang ada di lingkungannya, anak akan dengan mudah merespon apapun yang ia dapatkan dari lingkungannya (Yuliani Nurani, 2005: 139). Pada masa ini proses peniruan anak terhadap segala sesuatu yang ada di sekitarnya semakin meningkat. Peniruan tidak saja pada perilaku yang ditunjukkan oleh orang-orang di sekitarnya tetapi juga terhadap tokoh-tokoh yang sering dilihat dilingkungannya. Perlahan namun pasti anak menjadi pribadi yang digambarkan dari tokoh-tokoh tersebut.

Selain itu kebiasaan dan keteladanan juga merupakan faktor penting untuk bertindak baik. bila anak-anak sudah dibiasakan bertindak baik dalam hal-hal yang kecil. la akan lebih mudah untuk melakukan tindakan baik dalam hal yang lebih besar. maka penting dalam pembinaan kebiasaan-kebiasaan yang baik dilatihkan dalam kehidupan sehari-hari. Untuk dapat mempunyai moral baik dan benar anak tidak cukup sekedar melakukan tindakan yang dapat dinilai dengan baik dan bear. Anak dapat dikatakan sungguh-sungguh berbudi baik apabila tindakannya disertai dengakeyakinan dan pemahaman akan kebaikan yang tertanam dalam tindakan-tindakan tersebut. untuk memahami dan menyakininya anak perlu mengalami proses pengolahan atas peristiwa dan pengalaman hidup yang berkaitan dengan dirinya maupun dengan orang lain. Peristiwa dan pengalaman hidup yang diolah, dialami, dan dimaknai inilah yang akan menjadikan anak bermoral baik secara sejati 
maupun hakiki. Anak berbuat baik karena ia tahu dan yakin akan apa yang dilakukan.

Disisi lain identitas bangsa muncul dalam bentuk kebanggaan terhadap nilai moral dan agama, lingkungan, budaya, dan karakter bangsa. Berbagai kalangan menyatakan bahwa pada saat ini telah terjadi krisis identitas pada masyarakat Indonesia dengan semakin menguatnya perilaku-perilakuagresif seperti sering tawuran antar pelajar bahkan dengan guru, penyalahgunaan obat-obat terlarang, pelecehan seksual, pergaulan bebas, perilaku dengan meniru budaya asing yang tidak sesuai kepribadian bangsa serta tendensi meningkatnya perilaku individualis, mementingkan golongan di atas kepentingan bangsa.

Krisis identitas tersebut berdampak pada munculnya krisis ideology, krisis karakter, serta krisis kepercayaan masyarakat terhadap kepemimpinan. Dalam perspektif panjang fenomena tersebut dapat mengancam moral, mentalis dan mengikis rasa kebangsaan sehingga membahayakan integritas bangsa. Dalam upaya mengurangi dampak fenomena tersebut dipandang perlu adanya pengembangan nilai moral dan agama melalui jalur pendidikan secara intensif, termasuk melalui Pendidikan Anak Usia Dini (PAUD) (DisDik Jateng, 2015:16). Pendidikan anak usia dini bertujuan membentuk watak dan peradaban bangsa yang bermartabat dengan mengambangkan potensi tunas bangsa agar menjadi pribadi yang berkualitas dalam kerangka sebagai warga Negara yang bertanggung jawab (Peraturan Menteri Pendidikan:3).

Pendidikan anak usia dini juga dijelaskan dalam Permendikbud 146 tahun 2014 pasal 1 sebagai suatu upaya pembinaan yang ditujukan kepada anak sejak lahir sampai dengan usia 6 (enam) tahun yang dilakukan melalui pemberian rangsangan pendidikan untuk membantu pertumbuhan dan perkembangan jasmani dan rohani agar anak memiliki kesiapan dalam memasuki pendidikan lebih lanjut (Peraturan Menteri Pendidikan: 16).

Hasil observasi tanggal 5-6 Desember 2016 di KB Amanah Guwo Tlogowungu Pati $70 \%$ anak laki-laki yang ada dalam kelas KB 1 setiap harinya selalu melakukan tindakan kekerasan dengan memukul, menendang, menindih, dan mencakar. Menurut anak-anak tersebut mereka sedang memerankan tokoh-tokoh dalam acara televisi seperti Ultraman, Bima X, Bobo boy, dan Power Rangers. Dalam 
pandangan anak-anak, mereka adalah tokoh-tokoh idola mereka sebagai pahlawan kebajikan di dunia. Tanpa mereka ketahui, anak-anak justru melakukan sebaliknya, bukan sikap perilaku yang melindungi akan tetapi sikap perilaku yang menyakiti (Observasi, 5-6 Desember 2016).

Berdasarkan permasalahan tersebut menumbuhkan perhatian penulis selaku guru dalam pendidikan anak usia dini untuk membahas lebih lanjut tentang nilai-nilai moral pada anak. Untuk mengimbangi pengalaman anak melalui pembelajaran yang dilakukan mencoba andil dalam mengarahkan paradigma anak didik untuk lebih mengenal perilaku baik melalui metode bercerita sebagai implementasi nilai-nilai moral. Bercerita adalah menuturkan sesuatu yang mengisahkan tentang perbuatan atau suatu kejadian dan disampaakan secara lisan dengan tujuan membagikan pengalaman dan pengetahuan kepada orang lain. Dalam konteks komunikasi bercerita adalah upaya mempengaruhi orang lain melalui ucapan dan penuturan tentang sesuatu (ide). Sementara dalam konteks pembelajaran anak usia dini bercerita dapat dikatakan sebagai upaya untuk mengembnagkan potensi kemampuan berbahasa anak melalui pendengaran dan kemudian menuturkannya kembali dengan tujuan melatih ketrampilan anak dalam bercakap-cakap dan penanaman moral untuk menyampaikan ide dalam bentuk lisan (Bachri S, Bachtiar, 2005:10).

Peneliti mengangkat cerita dari jenis prosa lama berbentuk dongeng dan hikayat. Dongeng adalah cerita tentang sesuatu yang tidak masuk akal, dan tidak benar terjadi, dan bersifat fantastis atau khayal. Sedangkan hikayat adalah cerita yang melukiskan kehidupan raja atau dewa yang bersifat khayal. Peneliti mencoba melakukan penelitian dengan judul "Upaya Meningkatkan Nilai-nilai Moral Anak Usia 3-4 Melalui Metode Cerita di KB Amanah Guwo Tlogowungu Pati Tahun Pelajaran 2016/2017.

\section{DISKUSI}

Penelitian ini merupakan penelitian tindakan kelas, yang mengambil lokasi di KB Amanah Guwo Tlogowungu Pati pada tahun ajaran 2016/2017. Penelitian ini dilaksanakan selama 4 bulan yaitu bulan November 2016 s.d bulan Februari 2017. Pemilihan waktu penelitian ini disesuaikan dengan jadwal dan program semester yang digunakan sekolah bersangkutan sebagai tempat penelitian. Hasil penelitian dilaksanakan 
berdasarkan prosedur penelitian tindakan kelas melalui cerita untuk meningkatkan nilai-nilai moral anak di KB Amanah Guwo Pati. Hasil pengamatan awal pada proses pembelajaran sehari-hari di KB Amanah dapat disimpulkan bahwa nilai-nilai moral anak di KB Amanah masih kurang. Hal tersebut terlihat dari hasil pengamatan bahwa $70 \%$ anak laki-laki yang ada dalam kelas KB 1 setiap harinya selalu melakukan tindakan kekerasan dengan memukul, menendang, menindih, dan mencakar. Menurut anak-anak tersebut mereka sedang memerankan tokoh-tokoh dalam acara televisi seperti Ultraman, Bima X, Bobo boy, dan Power Rangers. Dalam pandangan anak-anak, mereka adalah tokoh-tokoh idola mereka sebagai pahlawan kebajikan di dunia. Tanpa mereka ketahui, anak-anak justru melakukan sebaliknya, bukan sikap perilaku yang melindungi akan tetapi sikap perilaku yang menyakiti.

Selain itu pembelajaran nilai-nilai moral anak juga kurang terperhatikan dan monoton, media yang digunakan dalam pembelajaran kurang menarik dan kurang bervariasi. Inovasi guru dalam pengembangan pembelajaranpun tidak berkembang. Hal ini menyebabkan anak tidak bersemangat dan pasif dalam pembelajaran yang mengembangkan nilainilai moral anaknya. Hasil pengamatan peneliti terhadap nilainilai moral anak anak melalui cerita sebelum diberikan tindakan adalah sebagai berikut:

Tabel 1. Data Hasil Pengamatan Nilai-nilai Moral Anak KB Amanah Sebelum Diberi Tindakan

\begin{tabular}{|c|l|c|c|c|c|c|c|}
\hline \multirow{2}{*}{ No } & \multicolumn{1}{|c|}{ Indikator } & $\mathbf{1}$ & $\mathbf{2}$ & $\mathbf{3}$ & $\mathbf{4}$ & $\begin{array}{c}\text { Jumlah } \\
\text { yang } \\
\text { tuntas }\end{array}$ & $\begin{array}{c}\text { Presentase } \\
\%\end{array}$ \\
\hline 1 & $\begin{array}{l}\text { Dapat membedakan tokoh } \\
\text { yang baik dan tidak }\end{array}$ & 4 & 10 & 6 & & 6 & $30 \%$ \\
\hline 2 & $\begin{array}{l}\text { Meniru tokoh baik yang ada } \\
\text { dalam cerita }\end{array}$ & 2 & 10 & 8 & & 8 & $40 \%$ \\
\hline 3 & $\begin{array}{l}\text { Mengetahui perasaan bersalah } \\
\text { dan rasa malu bila perilaku } \\
\text { anak tidak sesuai dengan } \\
\text { harapan }\end{array}$ & 4 & 9 & 7 & & 7 & $35 \%$ \\
\hline 4 & $\begin{array}{l}\text { Mengenal Tuhan melalui } \\
\text { ciptaanNya }\end{array}$ & 4 & 9 & 7 & & 7 & $35 \%$ \\
\hline
\end{tabular}


Keterangan:

1. Nilai-nilai moral anak belum tampak (belum tuntas)

2. Nilai-nilai moral anak mulai tampak (cukup tuntas)

3. Nilai-nilai moral anak sudah tampak (tuntas)

4. Nilai-nilai moral anak sudah tampak dan berkembang (tuntas sempurna)

Berdasarkan data pada proses pembelajaran sebelum diberikan tindakan menunjukkan bahwa indikator dapat membedakan tokoh yang baik dan tidak 30\% atau 6 anak tuntas, meniru tokoh baik yang ada dalam cerita $40 \%$ atau 8 anak tuntas, mengetahui perasaan bersalah dan rasa malu bila perilaku anak tidak sesuai dengan harapan $35 \%$ atau 7 anaktuntas, mengetahui tuhan melalui ciptaanNya $35 \%$ atau 7 anak tuntas.

Kondisi ini menunjukkan bahwa nilai-nilai moral anak-anak masih rendah, hal ini disebabkan karena kurangnya media pembelajaran dan proses pembelajaran kurang menarik sehingga anak merasa jenuh dan kurang tertarik mengikuti pembelajaran untuk meningkatkan nilai-nilai moral anak di kelas, oleh karena itu dalam pembelajaran diperlukan media dan metode yang tepat untuk menarik minat anak agar nilainilai moralnya berkembang. Melalui kegiatan cerita yang menarik dan menyenangkan diharapkan dapat memberikan pengalaman belajar bagi anak, sehingga nilai-nilai moral anak anak meningkat.

Siklus I dilaksanakan 5 kali pertemuan mulai hari Senin tanggal 12-14 Desember 2016 dilanjutkan tangal 3-4 Januari 2017 di KB Amanah Pati. Hasil pembelajaran nilai-nilai moral anak melalui cerita dengan tema rekreasi sub tema tempat rekreasi.

Pada siklus I sebelum peneliti melaksanakan penelitian pada waktu kegiatan bermain, peneliti menyusun perencanaan penelitian tindakan kelas dengan membuat Rencana Kegiatan Harian (RKH) sebagai berikut:

1. Berbaris, salam, berdo'a, iqrar

2. Kegiatan jasmani

3. Toilet training, melakukan percakapan tentang tema rekreasi sub tema rekreasi, dan alat-alat yang dipakai waktu rekreasi.

4. Kegiatan dilanjutkan pada peningkatan nilai-nilai moral anak melalui cerita. 
5. Bahan dan alat yang digunakan pada siklus I adalah white board dan langsung.

Dalam siklus I dibantu oleh beberapa teman sejawat yang memegang kelas untuk mengamati, mencatat dan mendokumentasi segala permasalahan yang terjadi selama proses Siklus I. Untuk melihat apakah cerita dapat meningkatkan nilai-nilai moral anak pada siklus 1 dilakukan pengamatan. Hasil pengamatan dapat diamati dari kegiatan yang dilakukan yaitu:

Tabel 2. Indikator Dapat Membedakan Tokoh Yang Baik dan Tidak

\begin{tabular}{|c|c|c|c|}
\hline \multirow{2}{*}{ No } & \multirow{2}{*}{ Kategori } & \multicolumn{2}{|c|}{ Membedakan Tokoh } \\
\hline & & Jumlah anak & Persentase Penilaian \\
\hline 1. & 1 (belum tuntas) & 1 & $5 \%$ \\
\hline 2. & 2 (cukup tuntas) & 6 & $30 \%$ \\
\hline 3. & 3 (tuntas) & 7 & $35 \%$ \\
\hline 4. & 4 (tuntas sempurna) & 6 & $30 \%$ \\
\hline & Jumlah & 20 & $100 \%$ \\
\hline
\end{tabular}

Dari tabel di atas dapat ditarik kesimpulan dapat membedakan tokoh yang baik dan tidak 30\% atau 6 anak dalam kategori tuntas sempurna, 35\% atau 7 anak dalam kategori tuntas, $30 \%$ atau 6 anak dalam kategori cukup tuntas, dan 5\% atau 1 anak dalam kategori belum tuntas.

Tabel 3. Indikator Meniru Tokoh Baik yang Ada dalam Cerita

\begin{tabular}{|c|c|c|c|}
\hline \multirow{2}{*}{ No } & \multirow{2}{*}{ Kategori } & \multicolumn{2}{|c|}{ Meniru Tokoh } \\
\cline { 3 - 4 } & & Jumlah anak & Persentase Penilaian \\
\hline 1. & 1 (belum tuntas) & 1 & $5 \%$ \\
\hline 2. & 2 (cukup tuntas) & 6 & $30 \%$ \\
\hline 3. & 3 (tuntas) & 7 & $35 \%$ \\
\hline 4. & 4 (tuntas sempurna) & 6 & $30 \%$ \\
\hline \multicolumn{2}{r|}{ Jumlah } & $\mathbf{2 0}$ & $\mathbf{1 0 0 \%}$ \\
\hline
\end{tabular}

Dari tabel di atas dapat ditarik kesimpulan meniru tokoh baik yang ada dalam cerita $30 \%$ atau 6 anak dalam kategori tuntas sempurna, 35\% atau 7 anak dalam kategori tuntas, 30\% atau 6 anak dalam kategori cukup tuntas, dan $5 \%$ atau 1 anak dalam kategori belum tuntas. 
Tabel 4. Indikator Mengetahui Perasaan Bersalah dan Rasa Malu bila Perilaku Anak Tidak Sesuai dengan Harapan

\begin{tabular}{|c|c|c|c|}
\hline \multirow{2}{*}{ No } & \multirow{2}{*}{ Kategori } & \multicolumn{2}{|c|}{ Mengetahui perasaan } \\
\cline { 3 - 4 } & & Jumlah anak & Persentase Penilaian \\
\hline 1. & 1 (belum tuntas) & 3 & $15 \%$ \\
\hline 2. & 2 (cukup tuntas) & 7 & $35 \%$ \\
\hline 3. & 3 (tuntas) & 7 & $35 \%$ \\
\hline 4. & 4 (tuntas sempurna) & 3 & $15 \%$ \\
\hline & Jumlah & $\mathbf{2 0}$ & $\mathbf{1 0 0} \%$ \\
\hline
\end{tabular}

Dari tabel di atas dapat ditarik kesimpulan mengetahui perasaan bersalah dan rasa malu bila perilaku anak tidak sesuai dengan harapan $15 \%$ atau 3 anak dalam kategori tuntas sempurna, 35\% atau 7 anak dalam kategori tuntas, $35 \%$ atau 7 anak dalam kategori cukup tuntas, dan $15 \%$ atau 3 anak dalam kategori belum tuntas.

Tabel 5. Indikator Mengenal Tuhan Melalui Ciptaan-Nya

\begin{tabular}{|c|c|c|c|}
\hline \multirow{2}{*}{ No } & \multirow{2}{*}{ Kategori } & \multicolumn{2}{|c|}{ Mengenal Tuhan } \\
\cline { 3 - 4 } & & Jumlah anak & Persentase Penilaian \\
\hline 1. & 1 (belum tuntas) & 2 & $10 \%$ \\
\hline 2. & 2 (cukup tuntas) & 6 & $30 \%$ \\
\hline 3. & 3 (tuntas) & 7 & $35 \%$ \\
\hline 4. & 4 (tuntas sempurna) & 5 & $25 \%$ \\
\hline \multicolumn{2}{r}{ Jumlah } & $\mathbf{2 0}$ & $\mathbf{1 0 0 \%}$ \\
\hline
\end{tabular}

Dari tabel di atas dapat ditarik kesimpulan Mengenal Tuhan melalui ciptaanNya $25 \%$ atau 5 anak dalam kategori tuntas sempurna, 35\% atau 7 anak dalam kategori tuntas, 30\% atau 6 anak dalam kategori cukup tuntas, dan 10\% atau 2 anak dalam kategori belum tuntas. 
Tabel 6. Rangkuman Hasil Persentase Nilai-nilai Moral Anak untuk Indikator Tuntas Pada Siklus I

\begin{tabular}{|c|c|c|c|c|c|c|c|}
\hline \multirow{2}{*}{ No } & \multirow{2}{*}{ Indikator } & \multicolumn{4}{|c|}{ Penilaian } & \multirow{2}{*}{$\begin{array}{l}\text { Jumlah } \\
\text { yang } \\
\text { tuntas }\end{array}$} & \multirow{2}{*}{ Presentase $\%$} \\
\hline & & 1 & 2 & 3 & 4 & & \\
\hline 1. & $\begin{array}{ll}\text { Mampu } & \text { mengenal } \\
\text { lingkungan } & \text { sekitarnya } \\
\text { melalui panca indra } & \end{array}$ & 1 & 6 & 7 & 6 & 13 & $65 \%$ \\
\hline 2. & $\begin{array}{l}\text { Terbiasa membuang } \\
\text { sampah pada tempatnya }\end{array}$ & 1 & 6 & 7 & 6 & 13 & $65 \%$ \\
\hline 3. & $\begin{array}{l}\text { Mampu memberi makan } \\
\text { binatang peliharaan }\end{array}$ & 3 & 7 & 7 & 3 & 10 & $50 \%$ \\
\hline 4. & $\begin{array}{ll}\text { terbiasa merawat dan } \\
\text { melindungi tanaman }\end{array}$ & 2 & 6 & 7 & 5 & 12 & $60 \%$ \\
\hline
\end{tabular}

Proses pembelajaran sebelum diberikan tindakan menunjukkan bahwa indikator dapat membedakan tokoh yang baik dan tidak $65 \%$ atau 13 anak tuntas, meniru tokoh baik yang ada dalam cerita $65 \%$ atau 13 anak tuntas, mengetahui perasaan bersalah dan rasa malu bila perilaku anak tidak sesuai dengan harapan $50 \%$ atau 10 anak tuntas, Mengenal Than melalui ciptaanNya 60\% atau 12 anak tuntas. Dapat kita ketahui bahwa melalui cerita nilai-nilai moral anak meningkat, meskipun masih jauh dari ketuntasan keberhasilan yang telah disepakati.

Dapat disimpulkan bahwa melalui cerita nilai-nilai moral anak belum sepenuhnya mencapai keberhasilan yang telah ditetapkan. Karena kriteria keberhasilan peningkatan nilai-nilai moral anakdidik dalam penelitian tindakan kelas ini apabila anak didik lebih dari $80 \%$ sedangkan yang dicapai dari keseluruhan aspek baru $60 \%$. Angka ini masih jauh dibawah angka keberhasilan. Dalam refleksi siklus I ini, peneliti dan kolabolator yaitu guru sepakat untuk memperbaiki kekurangan pada tiap aspek indikator Pelaksanaan pembelajaran di tindakan siklus I peneliti dan pendidik sepakat untuk meningkatkan sistem pembelajaran di kelas dengan memperhatikan hal -hal sebagai berikut :

1. Kegiatan awal sebaiknya dibuat lebih menarik agar berkesan dan menyenangkan.

2. Mendekati dan membimbing anak dalam mengerjakan tugas lebih terfokus kepada individu yang masih belum mandiri. 
3. Menambah reward baik berupa pujian maupun hadiah kecil.

4. Media dibuat lebih menarik.

5. Lebih komunikatif

6. Tidak memaksakan kehendak peneliti terhadap anak.

Deskripsi data hasil implementasi peningkatan nilai-nilai moral anak anak melalui cerita pada siklus I, anak-anak memperhatikan cara guru dalam kegiatan tema rekreasi ke pantai. Anak-anak bermain dengan tertib meski ada anak yang perlu ditambah motivasi untuk mencoba kegiatan. Hasil Pengamatan siklus I sudah baik karena anak antusias mengikuti kegiatan di area. Pada penelitian siklus I tingkat pencapaian peningkatan nilai-nilai moral anak anak melalui cerita masih kurang yaitu $60 \%$ karena pencapaian peningkatan nilai-nilai moral anak minimal $80 \%$ maka peneliti dan rekan kerja melakukan perencanaan ulang pembelajaran di siklus II. Peningkatan nilai-nilai moral anak selanjutnya dilakukan di siklus II dengan kegiatan cerita. Diharapkan melalui kegiatan ini nilai-nilai moral anak lebih optimal sehingga tingkat pencapaian perkembangan anak dapat mencapai standar minimal atau lebih baik lagi.

Pembelajaran peningkatan nilai-nilai moral anak pada siklus II dilaksanakan 5 kali pertemuan. Kegiatan dimulai pada hari Senin tanggal 9 s/d Jumat 13 Januari 2017 di KB Amanah dengan tema rekreasi, sub tema kendaraan darat dan udara, kendaraan laut.

Pada siklus II sebelum peneliti melaksanakan penelitian pada waktu kegiatan bermain, peneliti menyusun perencanaan penelitian tindakan kelas dengan membuat Rencana Kegiatan Harian (RKH) dimana sebelum kegiatan bermain anak - anak melakukan:

1. Berbaris, salam, berdo'a, iqrar

2. Kegiatan jasmani

3. Melakukan percakapan tentang tema rekreasi sub tema kendaraan darat dan udara, kendaraan laut.

4. Kegiatan dilanjutkan pada peningkatan nilai-nilai moral anak anak melalui cerita

5. Bahan dan alat yang digunakan pada siklus II adalah alat main di area, White board. Buku cerita 
Dalam siklus II ini peneliti dibantu oleh beberapa teman sejawat yang memegang sentra untuk mengamati, mencatat dan mendokumentasi segala permasalahan yang terjadi selama proses Siklus II. Sehingga peneliti dapat mengetahui kekurangan pada Siklus II dan melakukan tindakan selanjutnya apabila diperlukan.

Anak memulai kegiatan dengan menjawab dan memberi salam, berdoa, iqrar, toilet training, kegiatan jasmani, percakapan tentang tema pembelajaran, menyanyi, penjelasan kegiatan, aturan main, transisi kelompok kecil. Dilanjutkan dengan Bercerita tentang "Habibi dan Pesawat Indonesia". Seteleh bercerita para siswa diijinkan untuk istirahat sejenak Cuci tangan , makan bekal, dan bermain out door. Recalling, cuci tangan, berdoa sebelu makan, makan bekal, berdo'a selesai makan, pemberian reward kepada anak, berdoa pulang.

Untuk melihat apakah cerita dapat meningkatkan nilai-nilai moral anak pada siklus II dilakukan pengamatan. Hasil pengamatan yang dilakukan yaitu:

Tabel 7. Indikator dapat Membedakan Tokoh yang Baik dan Tidak

\begin{tabular}{|c|c|c|c|}
\hline \multirow{2}{*}{ No. } & \multirow{2}{*}{ Kategori } & \multicolumn{2}{|c|}{ Membedakan Tokoh } \\
\cline { 3 - 4 } & & Jumlah anak & Persentase Penilaian \\
\hline 1. & 1 (belum tuntas) & & \\
\hline 2. & 2 (cukup tuntas) & 3 & $15 \%$ \\
\hline 3. & 3 (tuntas) & 9 & $45 \%$ \\
\hline 4. & 4 (tuntas sempurna) & 8 & $40 \%$ \\
\hline \multicolumn{2}{r}{ Jumlah } & $\mathbf{2 0}$ & $\mathbf{1 0 0 \%}$ \\
\hline
\end{tabular}

Dari tabel di atas dapat ditarik kesimpulan dapat membedakan tokoh yang baik dan tidak $40 \%$ atau 8 anak dalam kategori tuntas sempurna, $45 \%$ atau 9 anak dalam kategori tuntas, $15 \%$ atau 3 anak dalam kategori cukup tuntas. 
DWI SULISTYANINGRUM

Tabel 8. Indikator Meniru Tokoh Baik Yang Ada Dalam Cerita

\begin{tabular}{|c|c|c|c|}
\hline \multirow{2}{*}{ No. } & \multirow{2}{*}{ Kategori } & \multicolumn{2}{|c|}{ Meniru Tokoh } \\
\cline { 3 - 4 } & & Jumlah anak & Persentase Penilaian \\
\hline 1. & 1 (belum tuntas) & 3 & $15 \%$ \\
\hline 2. & 2 (cukup tuntas) & 10 & $50 \%$ \\
\hline 3. & 3 (tuntas) & 7 & $35 \%$ \\
\hline 4. & 4 (tuntas sempurna) & $\mathbf{2 0}$ & $\mathbf{1 0 0 \%}$ \\
\hline \multicolumn{2}{r}{ Jumlah } &
\end{tabular}

Dari tabel di atas dapat ditarik kesimpulan meniru tokoh baik yang ada dalam cerita $37 \%$ atau 7 anak dalam kategori tuntas sempurna, $50 \%$ atau 10 anak dalam kategori tuntas, $15 \%$ atau 3 anak dalam kategori cukup tuntas.

Tabel 9. Indikator Mengetahui Perasaan Bersalah dan Rasa Malu Bila Perilaku Anak Tidak Sesuai dengan Harapan

\begin{tabular}{|c|c|c|c|}
\hline \multirow{2}{*}{ No } & \multicolumn{2}{|c|}{ Kategori } & \multicolumn{2}{|c|}{ Mengetahui perasaan } \\
\cline { 3 - 4 } & & Jumlah anak & Persentase Penilaian \\
\hline 1 & 1 (belum tuntas) & 4 & $20 \%$ \\
\hline 2 & 2 (cukup tuntas) & 8 & $40 \%$ \\
\hline 3 & 3 (tuntas) & 8 & $40 \%$ \\
\hline 4 & 4 (tuntas sempurna) & $\mathbf{2 0}$ & $\mathbf{1 0 0 \%}$ \\
\hline \multicolumn{2}{|c|}{ Jumlah } &
\end{tabular}

Dari tabel di atas dapat ditarik kesimpulan mengetahui perasaan bersalah dan rasa malu bila perilaku anak tidak sesuai dengan harapan $40 \%$ atau 8 anak dalam kategori tuntas sempurna, $40 \%$ atau 8 anak dalam kategori tuntas, $20 \%$ atau 4 anak dalam kategori cukup tuntas.

Tabel 10. Indikator Mengenal Tuhan melalui Ciptaan-Nya

\begin{tabular}{|c|l|c|c|}
\hline \multirow{2}{*}{ No } & \multirow{2}{*}{ Kategori } & \multicolumn{2}{|c|}{ Mengenal Tuhan } \\
\cline { 3 - 4 } & & Jumlah anak & Persentase Penilaian \\
\hline 1 & 1 (belum tuntas) & 2 & $10 \%$ \\
\hline 2 & 2 (cukup tuntas) & 12 & $60 \%$ \\
\hline 3 & 3 (tuntas) & 6 & $30 \%$ \\
\hline 4 & 4(tuntas sempurna) & $\mathbf{2 0}$ & $\mathbf{1 0 0 \%}$ \\
\hline \multicolumn{2}{|r|}{ Jumlah } \\
\hline
\end{tabular}


Dari tabel di atas dapat ditarik kesimpulan Mengenal Tuhan melalui ciptaanNya $30 \%$ atau 6 anak dalam kategori tuntas sempurna, $60 \%$ atau 12 anak dalam kategori tuntas, $10 \%$ atau 2 anak dalam kategori cukup tuntas.

Tabel 11. Rangkuman Hasil Persentase Nilai-nilai Moral Anak untuk Indikator Tuntas Pada Siklus II

\begin{tabular}{|c|c|c|c|c|c|c|c|}
\hline \multirow[b]{2}{*}{ No } & \multirow[b]{2}{*}{ Indikator } & \multicolumn{4}{|c|}{ Penilaian } & \multirow{2}{*}{$\begin{array}{c}\text { Jumlah } \\
\text { yang } \\
\text { tuntas }\end{array}$} & \multirow[b]{2}{*}{ Presentase \% } \\
\hline & & 1 & 2 & 3 & 4 & & \\
\hline 1 & $\begin{array}{l}\text { Dapat membedakan tokoh } \\
\text { yang baik dan tidak }\end{array}$ & & 3 & 9 & 8 & 17 & $85 \%$ \\
\hline 2 & $\begin{array}{l}\text { Meniru tokoh baik yang ada } \\
\text { dalam cerita }\end{array}$ & & 3 & 10 & 7 & 17 & $85 \%$ \\
\hline 3 & $\begin{array}{l}\text { Mengetahui } \\
\text { bersalah dan rasa malu bila } \\
\text { perilaku anak tidak sesuai } \\
\text { dengan harapan }\end{array}$ & & 4 & 8 & 8 & 16 & $80 \%$ \\
\hline 4 & $\begin{array}{l}\text { Mengenal Tuhan melalui } \\
\text { ciptaanNva }\end{array}$ & & 2 & 12 & 6 & 18 & $90 \%$ \\
\hline
\end{tabular}

Berdasarkan data di atas pada proses pembelajaran sebelum diberikan tindakan menunjukkan bahwa indikator dapat membedakan tokoh yang baik dan tidak $85 \%$ atau 17 anak tuntas, meniru tokoh baik yang ada dalam cerita $85 \%$ atau 17 anak tuntas, mengetahui perasaan bersalah dan rasa malu bila perilaku anak tidak sesuai dengan harapan $80 \%$ atau 16 anak tuntas, Mengenal Tuhan melalui ciptaanNya 90\% atau 18 anak tuntas. Dapat kita ketahui bahwa melalui cerita nilai-nilai moral anak meningkat sebesar $25 \%$ dari total nilai ketuntasan sebesar $60 \%$ naik menjadi $85 \%$.

Pembelajaran peningkatan nilai-nilai moral anak pada siklus ॥ dilaksanakan 5 kali pertemuan. Kegiatan dimulai pada hari Senin tanggal 9 s/d Jumat 13 Januari 2017 di KB Amanah dengan tema rekreasi, sub tema kendaraan darat dan udara, kendaraan laut. Pembelajaran dimulai dari perencanaan, pelaksanaan dan pengamatan.

Nilai-nilai moral adalah sistem kepercayaan, penghargaan, dan ketetapan tentang perbuatan benar dan salah yang terbentuk dari kebiasaan-kebiasan dari standar sosial yang dipengaruhi 
dari luar individu atau sesuai dengan harapan masyarakat atau kelompok sosial tertentu.

Kenyataan yang terjadi hasil observasi nilai-nilai moral anak di KB Amanah masih kurang. Hal tersebut disebabkan disebabkan pembelajaran yang berpusat pada anak untuk sementara ini masih jauh dari yang diinginkan. Hal ini dibuktikan dengan kenyataan di lapangan. bahwa proses pembelajaran di KB Amanah cenderung tidak mengembangkan cara berfikir kritis, kreatif, dan inovatif tetapi hanya memperkokoh kemampuan otak kiri.

Selain itu pembelajaran nilai-nilai moral anak juga kurang terperhatikan dan monoton, media yang digunakan dalam pembelajaran kurang menarik dan kurang bervariasi. Inovasi guru dalam pengembangan pembelajaranpun tidak berkembang. Hal ini menyebabkan anak tidak bersemangat dan pasif dalam pembelajaran yang mengembangkan nilainilai moral anaknya.

Keadaan nilai-nilai moral anak KB Amanah saat dilakukan observasi pra siklus adalah:

1. Dapat membedakan tokoh yang baik dan tidak $30 \%$

2. Meniru tokoh baik yang ada dalam cerita $40 \%$

3. Mengetahui perasaan bersalah dan rasa malu bila perilaku anak tidak sesuai dengan harapan $35 \%$

4. Mengenal Tuhan melalui ciptaanNya 35\%

Kondisi ini menunjukkan bahwa nilai-nilai moral anak masih rendah. Anak belum merasakan belajar dengan nyaman, metode yang dipakai terkesan memaksa, sehingga anak hanya mengikuti dan meniru penjelasan yang ada tanpa berani menuangkan ide dan kreativitasnya. Kepekaan anak terhadap nilai-nilai moral juga kurang.

Dalam kehidupan manusia, nilai berperan sebagai standar yang mengarahkan tingkah laku. Nilai membimbing individu untuk memasuki suatu situasi dan bagaimana individu bertingkah laku dalam situasi tersebut. nilai memberi arah pada sikap, keyakinan dan tingkah laku seseorang serta memberi pedoman untuk memilih tingkah laku yang diinginkan pada setiap individu.

Kegiatan yang bertujuan meningkatkan nilai-nilai moral anak pada penelitian ini dilakukan dua siklus. Setiap siklus dilakukan pertemuan 10 kali. Siklus pertama dimulai pada tanggal 12-16 Desember 2016 dilanjutkan tanggal 3-7 Januari 
2017. Sedangkan siklus kedua dilaksanakan pada tanggal 920 Januari 2017.

Pada siklus pertama anak mendengarkan cerita tentang sekolahku, keluargaku, gejala alam, air udara api, rekreasi ke pantai, tsunami aceh, kapal nabi Nuh dengan tema pembelajaran rekreasi sub tema tempat rekreasi dan peralatan yang dipakai rekreasi. Semangat dan inisiatif anak untuk bermain terlihat sekali. Karena dari hasil pengamatan yang tuntas yaitu meningkat sebesar $60 \%$ dengan rincian sebagai berikut:

1. Dapat membedakan tokoh yang baik dan tidak $65 \%$

2. Meniru tokoh baik yang ada dalam cerita $65 \%$

3. Mengetahui perasaan bersalah dan rasa malu bila perilaku anak tidak sesuai dengan harapan $50 \%$

4. Mengenal Tuhan melalui ciptaanNya $60 \%$

Peningkatan ini terjadi karena anak-anak bersemangat melakukan kegiatan dan merasa tertantang bermain di area yang disediakan. Selanjutnya pada siklus II kegiatan dilaksanakan mulai tanggal 9- 20 Januari 2017, dengan tema rekreasi sub tema kendaraan darat dan udara, dan kendaraan laut. Tema cerita adalah Habibi danpeswat Indonesia, Ke rumah Nenenk dengan bis kota, stasiun balapan, pembalap Ryan yang baik hati, unta nabi Sholeh, Kapal nabi Nuh, Kuda Nabi Muhammad, surga 1, surga 2.

Pada siklus dua anak mendapatkan pengalaman baru denganbahan bekas. Anak diberikan kebebasan berkreasi sesuai dengan imajinais mereka. dan hasil pengamatan menunjukkan bahwa nilai-nilai moral anak anak meningkat sebanyak $25 \%$ dari nilai $60 \%$ di siklus pertama meningkat menjadi $85 \%$. Dengan rincian:

1. Dapat membedakan tokoh yang baik dan tidak $85 \%$

2. Meniru tokoh baik yang ada dalam cerita $85 \%$

3. Mengetahui perasaan bersalah dan rasa malu bila perilaku anak tidak sesuai dengan harapan $80 \%$

4. Mengenal Tuhan melalui ciptaanNya $90 \%$

Berdasarkan hasil pengamatan maka dinyatakan bahwa nilainilai moral anak meningkat sebanyak $85 \%$ dari kriteria ketuntasan yang ditelah ditetapkan sebesar $80 \%$. Dan kegiatan cerita dapat meningkatkan kecerdasan naturalis. 


\section{SIMPULAN}

Kegiatan cerita untuk meningkatkan nilai-nilai moral anak di kelompok Bermain Amanah dilaksanakan dengan dua siklus, siklus I dengan cerita secara lisan tanpa gambar dengan tema sekolahku, keluargaku, gejala alam, air udara api, rekreasi ke pantai, tsunami aceh, kapal nabi nuh. Dan siklus II dibagi dengan buku cerita dengantema Habibi dan Pesawat Indonesia,ke rumah nenek naik bis kota, stasiun balapan, pembalap Ryan yang baik hati, unta nabii Sholeh, kuda nabi Muhammad, surga 1, dan surga 2.Melalui cerita menunjukkan adanya peningkatan dari pra siklus 35\% anak yang tuntas dalam nilai-nilai moral, naik di siklus I menjadi $65 \%$. Dan pada siklus II meningkat menjadi $85 \%$ dan terjadi peningkatan sebanyak $25 \%$. Hasil yang dicapai pada siklus II tersebut sudah memenuhi target ketuntasan yang telah ditetapkan, yaitu $80 \%$ dari keseluruhan anak mendapat nilai dengan kategori tuntas yaitu nilai 80 . Peningkatan nilai ratarata ini membuktikan keberhasilan cerita untuk meningkatkan nilai-nilai moral anak.

\section{REFERENSI}

Andriani, Durri. Metode Penelitian. Tangerang Selatan: Universitas Terbuka, 2012.

Aisyah, Siti. Perkembangan dan Konsep Dasar Pengembangan Anak Usia Dini. Jakarta: Universitas Terbuka, 2008.

Arikunto, Suharsimi. Prosedur Penelitian Suatu Pendekatan Praktik. Jakarta. Rineka Cipta, 2006.

Asfandiyar, Andi. Cara Pintar Mendongeng. Bandung: Dar Mizan, 2007.

Astuti, Henny P. Perkembangan Anak Usia Dini 1. Yogyakarta:Deepublish, 2013.

Bachri, Bachtiar S. Pengembangan Kegiatan Berceita di Taman Kanak-kanak Teknik dan Prosedurnya. Jakarta: Departemen Pendidikan Nasional, 2005.

Belet, S. Dilek and Sibel Dal. 2010. "The Use of Storytelling to Develop The Primary School Students "Critical Reading Skill: The Primary Education Pre-service Teachers" Opinions. Procedia Social and 
Behavioral Sciences (2010) 1830-1834". ProcediaSocial and Behavioral Sciences. www.sciencedirect.com. Diunduh Jum'at 13 April jam 10:03.

Delfita, Riri. Meningkatkan Kemampuan Berbahasa Anak Melalui Permainan Gambar dalam Bak Pasir di Taman Kanak-Kanak Bina Anaprasa Mekar Sari Padang. Jurnal Pesona PAUD VOL I NO. I. Diunduh Kamis, 2 Desember 2016, jam 12.16.

Dhieni, Nurbiana. Metode Pengembangan Bahasa. Jakarta: Universitas Terbuka. 2006.

Dinas Pendidikan Prov Jateng, Peraturan Menteri Pendidikan dan Kebudayaan Republik Indonesia nomor 146 tahun 2014 Tentang Standar Kurikulum 2013 Pendidikan Anak Usia Dini. Semarang: Dis dik Jateng. 2014.

DS, Agus. Tips Jitu Mendongeng. Yogyakarta: Kanisius, 2009.

Fredricks, Kathy. "Tell me a story". Digital Storytelling. http://web.ebscohost.com. Diunduh Minggu, 13 Juli 2016 jam 19:20.

Hurlock, Elizabeth, B. Perkembangan Anak. Jakarta: Erlangga, 1978.

Isnaini, Tri. Implementasi Metode Cerita Islami Dalam Menanamkan Moral Keagamaan Di TK Islam Terpadu Permata Hati Ngaliyan, Semarang: UIN Semarang, 2015.

Jamaris, Martini. Perkembangan dan Pengembangan Anak Usia Taman kanak-kanak. Jakarta: Universitas Negeri Jakarta, 2003.

Jundi, Abu. Teknik Bercerita untuk anak Usia Dini. Artikel (Online) http://abinejunadi.blogspot.com/2011/01/ teknik-bercerita-untuk-ank-usia-dini.html.diakses 12 Juni 2014, 2011,

Khusniyah, Mariatul. Efektifitas Dongeng Islami Terhadap Penalaran Moral Anak. Surakarta: UMS, 2009.

Mc Devitt Teresa $M$ dan Jeanne Ellis Ormrod, Child Development Educatioan and Working With Children and Adolescents, Pearson International Edition, Second Edition. (disampaikan dalam seminar perkembangan bahasa oleh Sabarti), 2004. 
Moeslichatun. Metode Pengajaran di Taman Kanak-kanak. Jakarta:Rineka Cipta, 1998.

Mulyati, Yeti. Materi Pokok Bahasa Indonesia. Jakarta: Universitas Terbuka, 2009.

Nurani, Yuliani Sujiono. Mencerdaskan Perilaku Anak Usia Dini. Jakarta: PT Elex Media Komputindo, 2005.

Poerwadarminto. Kamus Umum Bahasa Indonesia. Jakarta: Balai Pustaka, 2007.

Prihadi. Langkah-langkah Bercerita, http://www.Prihadipati. blogspot.co.id (diakses pada tanggal 9 Desember 2016 Pukul 06.03 WIB)

Ridluwan. Skala Pengukuran Variabel-variabel Penelitian. Bandung: Alfabeta, 2010.

Rusefania. Peningkatan Kosa Kata Bahasa Inggris Anak Melalui Permainan Tebak Suara dengan Kartu Gambar Binatang di PAUD Palapa 1 Kecamatan Batang Anai Kabupaten Padang Pariaman. FIP UNP.JurnalPesona PAUD. Vol. 1 No. 1. Diunduh 2 Desember 2016, jam 12.16, 2013.

Setiarsih, Fatma. Upaya Meningkatkan Minat Baca Anak Melalui Kegiatan Bercerita Berkarakter Islam di Kelompok Bermain Nurul Jannah Ngaliyan Semarang. Semarang: UNNES, 2012.

Sugiyono. Metode Penelitian Pendidikan Pendekatan Kuantitatif, Kualitatif dan $R \& D$. Bandung: Alfabeta, 2010.

Sulastri. Peningkatan Budi Pekerti Siswa Melalui Mata Pelajaran Bahasa Indonesia. J Jakarta: UNJ, 2006.

Suyanto, Slamet. Dasar-dasar Pendidikan Anak Usia Dini.Yogyakarta: Hikayat, 2005.

. Pembelajaran Untuk Anak TK. Jakarta: Depdiknas, 2005. 